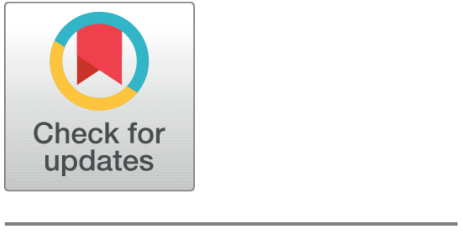

G OPEN ACCESS

Received: 22.12.2021

Accepted: 15.01.2022

Published: 04.02.2022

Citation: Paul MK, Mini KD, Benn AR, Mathew J (2022) Kurthia gibsonii Mb126 immobilised chitinase against Aspergillus flavus, a fungal pathogen linked to lemon postharvest deterioration. Indian Journal of Science and Technology 15(3): 136-145. https://doi.org/ 10.17485/IJST/v15i3.2387

* Corresponding author. minikpaul2016@gmail.com

Funding: None

Competing Interests: None

Copyright: (c) 2022 Paul et al. This is an open access article distributed under the terms of the Creative Commons Attribution License, which permits unrestricted use, distribution, and reproduction in any medium, provided the original author and source are credited.

Published By Indian Society for Education and Environment (iSee)

ISSN

Print: 0974-6846

Electronic: 0974-5645

\section{Kurthia gibsonii Mb126 immobilised chitinase against Aspergillus flavus, a fungal pathogen linked to lemon postharvest deterioration}

\author{
Mini K Paul ${ }^{1 *}$, K D Mini², Anu Ruby Benn ${ }^{1}$, Jyothis Mathew ${ }^{3}$ \\ 1 Department of biosciences, MES college, Aluva7, Kerala, Marampally, Ernakulam, India \\ 2 Assistant Professor, Department of Zoology, Sree Sankara college, Kerala, Kalady, \\ Ernakulam, India \\ 3 Professor, School of Biosciences, MG University, Kottayam, Kerala, India
}

\section{Abstract}

Background of the study: As fungi become resistant to commonly used pesticides, fungicides are becoming not only more expensive, but also less effective in controlling postharvest infections. New chitinase immobilisation techniques are urgently needed to minimize enzyme costs while enhancing bio catalytic performance, antifungal activity, enzyme stability, and reusability. Objectives: The objective of this study was to immobilise chitinase of Kurthia gibsonii Mb126 by entrapping it in calcium alginate beads and to analyse its antifungal activities against Aspergillus flavus. Methods: The optimal parameters influencing the immobilization process and the characteristics of soluble and immobilised chitinase of $K$. gibsonii Mb126 were analysed. The antifungal activities of immobilised and free chitinase of $K$. gibsonii Mb126 against $A$. flavus, which was isolated from decayed lemon fruit, were performed using the agar-disk diffusion method. Free chitinase $25.0 \mathrm{~mL}(0.8 \mathrm{U} / \mathrm{mL})$ and immobilised chitinase $0.06 \mathrm{~g}$ (specific activity $124-192 \mathrm{U} / \mathrm{mg}$ ) were treated on separate lemon fruits for testing antifungal activity against $A$. flavus. Findings: K. gibsonii Mb126 chitinase was immobilised perfectly in calcium alginate beads. After optimising process parameters of immobilisation (sodium alginate concentration $3 \%$, calcium chloride $0.2 \mathrm{M}, 120 \mathrm{~min}$. curing time), the specific activity of $K$. gibsonii Mb126 immobilised chitinase improved to 11.9-fold greater than the free form of chitinase and the immobilisation yield increased to $84 \%$. It was observed that the thermal stability and storage stability of immobilised chitinase were better than those of free enzymes. The immobilised chitinase could be reused, and it retained $78 \%$ activity even after 16 cycles. The surface morphology of immobilised chitinase was observed in a scanning electron microscope at different magnification powers. Enzyme kinetics was studied and compared with that of its chitinase soluble counterpart. An in vitro study demonstrated that immobilised chitinase of $K$. gibsonii Mb126 has higher antifungal activity against $A$. flavus. In vivo experimental study of the 
antifungal nature of chitinase in lemon fruits infected by $A$. flavus indicated that immobilised chitinase significantly decreased the incidence of postharvest decay. Conclusion: The immobilised chitinase of $K$. gibsonii Mb126 can be utilised as an important source of sustainable and environmentally friendly fungicides to prevent pathogens and saprophytic fungi from food. Novelty: To the best of our knowledge, this is the one and only study report about the antifungal nature of immobilised chitinase against a fungus that causes postharvest decay in lemon fruits.

Keywords: Kurthia gibsonii Mb126; Aspergillus flavus; immobilised chitinase; postharvest decay of lemon; sodium alginate

\section{Introduction}

Lemon fruits (Citrus limon L.) are a source of minerals, vitamins, and other essential growth factors that are needed for body metabolism. Spoilage accounts for eighteen to twenty-five percent of fruit production losses, particularly during the post-harvest stage $^{(1)}$. Due to the acidic nature (below 4 ), a lot of fungi infect lemon fruits. Fungi produce mycotoxins such as aflatoxin, patulin, and ochratoxin that are very dangerous to humans and animals ${ }^{(2)}$. Post-harvest spoilage of fruits can be managed by using chemical fungicides. However, the indiscriminate usage of chemical fungicides has significant negative impacts, such as increased cost, development of resistance to fungicides, risk of handling, negative public concern about pesticide residues on food and the environment, and threat to human health. In this scenario, intensified studies led to the discovery of alternative, safer natural food protectants having antifungal activity to preserve the quantity and quality of fruits.

Chitinase is an enzyme (E.C 3.2.2.14) that can hydrolyse chitin and is distributed in microorganisms, plants, and animals. Although catalytically efficient forms of chitinase with antifungal activity have been isolated and purified from different microorganisms ${ }^{(3)}$, some barriers, such as cost of production and purification, still limit the extensive biocontrol application of chitinase. In order to overcome these hurdles, continuous research on various techniques of immobilisation of enzymes is going on to replace the free enzyme. Immobilised enzymes have an extended shelf life, and it permits easy purification of the immobilised enzyme and products, and it facilitates the reusability of enzymes for several cycles ${ }^{(4)}$. The choice of the best material for support and the immobilisation technique are crucial factors for getting a better immobilisation yield.

In this study, we used the immobilisation technique "encapsulation." It is a major immobilisation method. Here the enzyme is encapsulated physically or chemically within a semi-permeable membrane ${ }^{(5)}$. In the encapsulation process, alginate is the preferred material because of its unique properties like mild gelation conditions, low cost, non-toxic, easy formulation, biocompatibility, and it also prevents microbial attack. Here we mixed alginate with clay to overcome disadvantages like excessive diffusion of enzyme from calcium alginate gel due to large pore size and weak mechanical strength ${ }^{(6)}$.

The objective of this study was to immobilise chitinase of K. gibsonii Mb126, one of the best chitinase producers, by entrapping it in calcium alginate beads and to analyse the optimal parameters influencing the immobilisation process. The characteristics of soluble and immobilised chitinase from K. gibsonii Mb126 were examined and compared. The antifungal activities of immobilised and free chitinase of $K$. gibsonii Mb126 against $A$. flavus, which was isolated from decayed lemon fruit, were performed using the agar-disk diffusion method. In vivo antifungal activities of immobilised 
chitinase on lemon fruits against $A$. flavus were performed.

\section{Materials and methods}

The enzyme used for the immobilisation process was chitinase from K. gibsonii Mb126, which was purified and stored at $4^{\circ} \mathrm{C}$ until use. All the reagents used in this study were analytical grade and were purchased from Sigma Aldrich. The enzyme activity of both free and immobilised chitinase was determined by the dinitrosalicylic acid methodusing $\mathrm{N}$-acetyl glucosamine and colloidal chitin as standard and substrate, respectively. One unit of chitinase was represented as the amount of enzyme sufficient to hydrolyse $1.0 \mathrm{~mol}$ of $\mathrm{N}$-acetyl glucosamine per minute under the standard experimental parameters. Protein concentration was determined using Lowry's method and the specific activity of chitinase of immobilised and soluble chitinase was determined as micromoles of $\mathrm{N}$-acetyl glucosamine produced per milligram of protein per minute.

\subsection{Immobilisation of chitinase on alginate beads}

The encapsulation of chitinase in calcium alginate-clay beads was performed with some changes according to the methodology of Ishita and Seemi, 2020) ${ }^{(7)}$. China clay finely powdered $(2.5 \%)$ was mixed in sodium phosphate buffer $(0.1 \mathrm{M}, \mathrm{pH} 7.0)$ and stirred for 1 hour. Sodium alginate powder $(2.5 \%)$ and $2.5 \mathrm{~mL}$ of glycerol were added to the mixture and stirred at $500 \mathrm{rpm}$ for 4 hours. Alginate-clay solution was combined with chitinase (with a specific activity of $10.31 \mathrm{U} / \mathrm{mg}$ ) in a blender (12:1). The amalgam was dropped into a $0.2 \mathrm{M}$ calcium chloride and stirred at $500 \mathrm{rpm}$ for 2 hours at $4^{\circ} \mathrm{C}$. The calcium alginate beads containing entrapped chitinase were separated by filtration and washed with distilled water to clear away unbound enzymes. After repeated washing, the beads were well dried and stored in buffer at $4^{\circ} \mathrm{C}$ until use. The percentage of immobilisation yield was calculated by the following equation:

$$
\text { Immobilization yield }(\%)=\frac{\text { specific activity of immobilised chitinase }}{\text { specific activity of free enzyme }} \times 100
$$

\subsection{Optimization of immobilization conditions}

Optimization of immobilisation conditions was carried out with 1-6\% sodium alginate and 0.1-0.6 M calcium chloride to estimate optimum conditions for the efficient polymerization of calcium alginate spheres with immobilised chitinase. The efficiency of immobilisation was also enhanced by optimising the curing time from 30.0 to 180.0 minutes.

\subsection{Characterization of immobilised and soluble chitinase}

The characterization of immobilised and soluble chitinase was carried out by determining the relative enzyme activity. The effect of reaction time on the enzymatic activity of soluble and immobilised chitinase was carried out with a colloidal chitin solution of $30.0 \mathrm{~g} \mathrm{~L}^{-1}$ at $40^{\circ} \mathrm{C}$ for different reaction times, i.e., 5.0 to 40.0 minutes. Temperature optimums for the soluble and immobilised enzymes were also determined by running assay reactions at various temperatures ranging from $20^{\circ} \mathrm{C}$ to $80^{\circ} \mathrm{C}$. Similarly, the optimum $\mathrm{pH}$ for the catalytic activity of soluble and immobilised chitinase was analysed in a pH range from 5.0 to 8.5 . Different buffers such as acetate buffer ( $\mathrm{pH}: 5.0-6.0$ ), citrate buffer ( $\mathrm{pH}: 5.0-6.0)$ and potassium phosphate buffer (pH: 7.0-8.5) with the same ionic strength $(100 \mathrm{mM}$ ) were used. The kinetic properties, $\mathrm{Km}$ and Vmax, of soluble and immobilised chitinase were determined using a Line weaver-Burk plot by conducting the enzymatic assay with different substrate concentrations.

The thermal stability of soluble and immobilised chitinase was investigated by conducting enzymatic reactions at different temperatures such as $40{ }^{\circ} \mathrm{C}, 50^{\circ} \mathrm{C}$, and $60^{\circ} \mathrm{C}$ for different time intervals (20.0-120.0 min) and analysing every 20.0-minute time interval.

The stability of chitinase after storage at $4^{\circ} \mathrm{C}$ was analysed by performing the assay every 5 days for 20 days. The influence of different chemicals such as tween-80, triton X-100, tween-20, SDS, mercaptoethanol, EDTA, and dithiothreitol was analysed by providing these chemicals at various concentrations $(2-10 \mathrm{mM})$ into the reaction system and the enzyme activity was determined. For the continuous utilisation of the enzyme, the relative activity of the immobilised chitinase was investigated by using $0.5 \mathrm{~g}$ of beads for several reaction cycles. After each cycle, the alginate sphere was washed with respective buffer and used again to perform catalytic function. The enzyme activity after the first cycle was considered as $100 \%$. Surface morphology of alginate spheres having the entrapped enzyme was observed under a scanning electron microscope of different magnification powers. 


\subsection{In vitro antifungal assay}

The antifungal properties of the immobilised chitinase of $K$. gibsonii Mb126 were determined using the agar-disk diffusion method. The pathogenic fungus A. flavus was isolated from decayed lemon fruits and utilised for in vitro antifungal assay. The fungi were inoculated into Potato Dextrose Agar (PDA) plates and, after seven days of incubation at $25^{\circ} \mathrm{C}$, fungal mycelia from pure culture were aseptically transferred to Sabouraud's dextrose broth and cultured for 10 days at $25^{\circ} \mathrm{C}$. Spores were taken and suspended in sterile water containing $0.05 \%$ Tween 80 . The concentration of spore suspension was kept at $10^{4}-10^{5} / \mathrm{mL}$.

Next, $100 \mu \mathrm{L}$ of spore suspension was spread on PDA plates and a sterile filter paper disc with a diameter of $5 \mathrm{~mm}$ was kept in the centre of the plates. Various concentrations of soluble chitinase $(0.1-0.8 \mathrm{U} / \mathrm{mL})$ and immobilised chitinase $(0.02-$ $0.16 \mathrm{~g}$ ) in $0.1 \mathrm{M}$ sodium phosphate buffer ( $\mathrm{pH} 7.0$ ) were applied to the disc in separate plates to determine mycelial inhibition. Negative control discs were applied with sterile distilled water. The plates were incubated at $28^{\circ} \mathrm{C}$ for 8 days, and the diameters of the inhibition zones around the discs were measured. All the tests were conducted in triplicate. The inhibition percentage of immobilised and free chitinase was determined by the following equation:

$$
\text { Inhibition }(\%)=\frac{[\mathrm{C}-\mathrm{T}]}{\mathrm{C}} \times 100
$$

C - Mycelial diameter in the control plate ( $\mathrm{mm})$.

$\mathrm{T}$ - Mycelial diameter in the treatment (Free/immobilised chitinase) plate ( $\mathrm{mm})$.

\subsection{In vivo antifungal assay}

The lemon fruits (Citrus limon) used in the experiments were obtained from local markets. Healthy fruits were taken and surface sterilised with $2.5 \%$ sodium hypochlorite solution. After multiple washes with distilled water and storage in a dry place to remove excess water on the surface until used for in vivo assay. Lemon fruits were scratched ( $3 \mathrm{~mm}$ depth) with a sterilised needle. Lemons were inoculated with spore suspension $\left(10^{4}-10^{5} / \mathrm{mL}\right)$ of A. flavus and dried in the air for $1 \mathrm{~h}$. Then, free chitinase $25.0 \mathrm{~mL}(0.8 \mathrm{U} / \mathrm{mL})$ and immobilised chitinase $0.06 \mathrm{~g}$ (specific activity $124-192 \mathrm{U} / \mathrm{mg}$ ) were treated on separate lemon fruits for testing antifungal activity against $A$. flavus. Fruits inoculated with only A. flavus were used as positive controls for each experiment. Fruits were then kept in covered plastic boxes for 9 days at room temperature, under a photoperiod of $12 \mathrm{~h}$ light and $12 \mathrm{~h}$ dark under storage conditions. Ten lemons, five replicates of each, were used for each of the treatments. During the storage, the percentage of decayed lemons was recorded.

\section{Results}

\subsection{Optimisation of Immobilisation conditions}

When sodium alginate is poured dropwise into calcium chloride, ionic bonds form between the carboxylate group of sodium alginate and calcium, leading to the synthesis of alginate beads ${ }^{(8)}$. Different concentrations of sodium alginate (1 to 6\%) were analysed to synthesise the stable alginate beads with the entrapped chitinase. Using $3 \%$ of sodium alginate, $65 \%$ of the immobilisation yield was obtained. It was found that lower and higher amounts of sodium alginate were not suitable for producing mechanically stable alginate beads. The concentration of sodium alginate determines the pore size of the alginate beads. A low concentration of sodium alginate synthesised soft beads and led to leakage of entrapped chitinase because of high porosity. In contrast, high concentration created a small pore size of the gel, which resulted in low penetration of the substrate (chitin). Therefore, a sodium alginate concentration of $3 \%$ was optimum for the formation of functionally active alginate spheres with the entrapped enzyme. Because the porous properties of alginate may cause entrapped chitinase to leak, sodium alginate was blended with china clay to for synthesising immobilised beads improve the mechanical stability of the immobilised chitinase. Kaolin (china clay) is a hydrated aluminium silicate and chemically inert.

Calcium chloride concentration is also important for the formation of a stable alginate sphere system. So, the concentration of calcium chloride from 0.1 to $0.6 \mathrm{M}$ was also optimised to enhance the immobilisation yield. The highest enzyme immobilisation yield was achieved at $84 \%$ with a $0.2 \mathrm{M} \mathrm{CaCl}_{2}$ solution. Below and above $0.2 \mathrm{M} \mathrm{CaCl} 2$, the immobilisation yield was low. The immobilisation yield decreased with a rise in calcium chloride concentration. It may be due to a change in $\mathrm{pH}$ with the change in calcium chloride concentration. Immobilisation yield was noticed at different curing times (30 to 180 minutes) and showed that immobilisation yield was directional proportional to prolonged time, and the extreme was obtained at 120 min. However, curing time after 120 minutes did not cause any advancement in the efficiency, perhaps due to the continuous hardness of the sphere. Gel formation did not happen at low curing time, and that resulted in lower immobilisation efficiency and enzyme leakage. After optimising process parameters (Table 1) of immobilisation (sodium alginate concentration of $3 \%, 0.2 \mathrm{M}$ calcium 
chloride, and $120 \mathrm{~min}$. curing time), the specific activity of entrapped chitinase improved to 11.9-fold in contrast with the soluble form of chitinase, and the immobilisation yield increased to $84 \%$.

Table 1. Optimization of immobilization conditions

\begin{tabular}{llllll}
\hline $\begin{array}{l}\text { Sodium alginate } \\
\text { concentration (\%) }\end{array}$ & $\begin{array}{l}\text { Immobilization } \\
\text { yield(\%) }\end{array}$ & $\begin{array}{l}\text { Calcium Chloride } \\
\text { Concentration }(\mathrm{M})\end{array}$ & $\begin{array}{l}\text { Immobilization } \\
\text { yield(\%) }\end{array}$ & $\begin{array}{l}\text { curing time } \\
(\mathrm{min} .)\end{array}$ & $\begin{array}{l}\text { Immobilization } \\
\text { yield(\%) }\end{array}$ \\
\hline 1 & $23 \pm 1.32$ & 0.1 & $53 \pm 1.65$ & 30 & $64 \pm 0.75$ \\
2 & $54 \pm 0.45$ & 0.2 & $84 \pm 1.23$ & 60 & $69 \pm 0.43$ \\
3 & $65 \pm 1.3$ & 0.3 & $64 \pm 1.67$ & 90 & $71 \pm 1.65$ \\
4 & $62 \pm 0.23$ & 0.4 & $59 \pm 0,68$ & 120 & $84 \pm 2.55$ \\
5 & $48 \pm 1.87$ & 0.5 & $48 \pm 1.3$ & 150 & $67 \pm 1.02$ \\
6 & $47 \pm 2.24$ & 0.6 & $48 \pm 1.3$ & 180 & $65 \pm 0.95$ \\
\hline
\end{tabular}

\subsection{Characterization of Soluble and immobilised chitinase}

In a scanning electron microscope with various magnification powers, the surface morphology of immobilised chitinase was examined (Figure 1). The reaction time of free chitinase with its substrate was compared to that of immobilised chitinase. Free chitinase catalysis reaction time was 10.0 minutes, while immobilised chitinase catalysis reaction time was 25.0 minutes (Figure 2). The time required for the substrate, chitin, to reach the active site of immobilised chitinase by diffusing through the alginate matrix may account for the 15.0-minute increase in reaction time of entrapped chitinase compared to free chitinase.

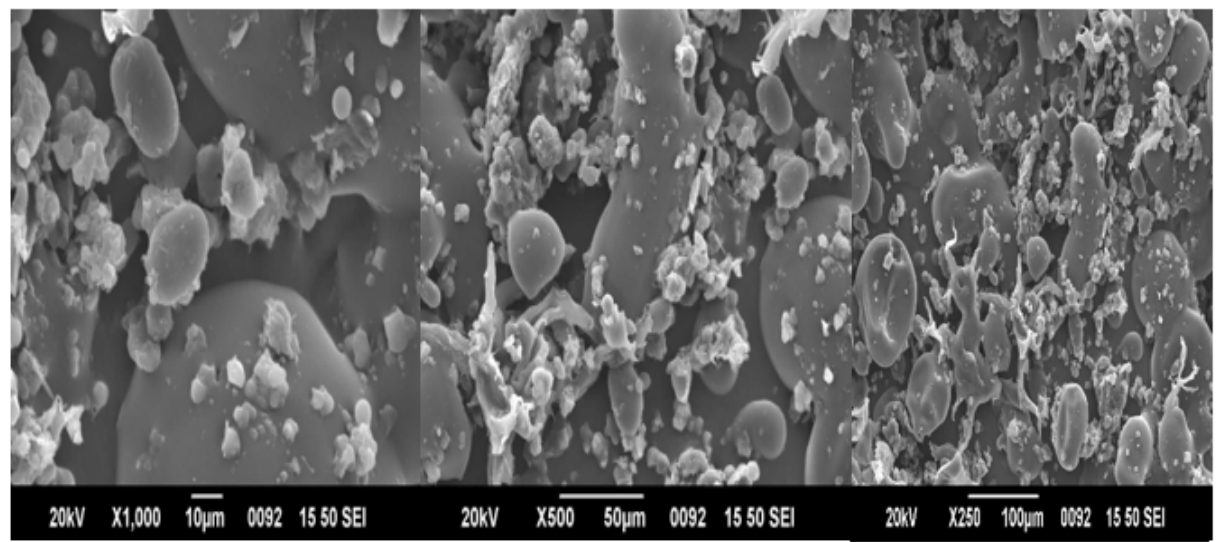

Fig 1. Surface characterization of immobilised K. gibsonii Mb126 chitinase under Scanning electron microscopy with different magnification power

By running enzyme assays at different temperatures $\left(20^{\circ} \mathrm{C}\right.$ to $\left.80^{\circ} \mathrm{C}\right)$, the optimal temperature of free and entrapped chitinase was determined. Free chitinase worked best at a temperature of $40{ }^{\circ} \mathrm{C}$. The temperature profile of immobilised chitinase was broader, with maximal activity between $35^{\circ} \mathrm{C}$ and $60^{\circ} \mathrm{C}$ and 65 percent activity even at $70{ }^{\circ} \mathrm{C}$ (Fig.3). Similarly, Trichoderma harzianum Chit 42 immobilised chitinase on chitosan beads had an optimum temperature of $45^{\circ} \mathrm{C}^{(9)}$.

The effect of $\mathrm{pH}$ on chitinase activity following immobilisation was measured at $\mathrm{pH}$ levels ranging from 5.0 to 8.5. (Figure 4). Over a wide variety of $\mathrm{pH}$ values, the immobilised enzyme activity outperformed the free enzyme. At an alkaline $\mathrm{pH}$, the relative activity of free enzymes decreases, but immobilised enzymes retain approximately 92 percent of their activity at $\mathrm{pH} 8.5$. At high $\mathrm{pH}$, the alginate matrix may protect the enzyme from denaturation. Trichoderma harzianum Chit42 immobilised chitinase performed best at $\mathrm{pH} 4^{(9)}$.

Various concentrations of chitin were utilised to calculate enzyme kinetics of soluble and immobilised chitinase. The Lineweaver-Burk plot has been used to determine the kinetic characteristics of free and immobilised chitinase. Km and Vmax values of the free chitinase were $11.1 \mathrm{mg} / \mathrm{mL}, 11.12 \mu$ moles $/ \mu \mathrm{g} \mathrm{h}$, respectively. The maximum rate of immobilised chitinase was observed with a Vmax value of $0.8 \mu$ moles $/ \mu$ gh and a Km value of $20 \mathrm{mg} / \mathrm{mL}$ (Fig. 5 ). The greater Km value might be due to the immobilised enzymes' lesser affinity for chitin than that of the unbound enzyme. Low affinity could be caused 


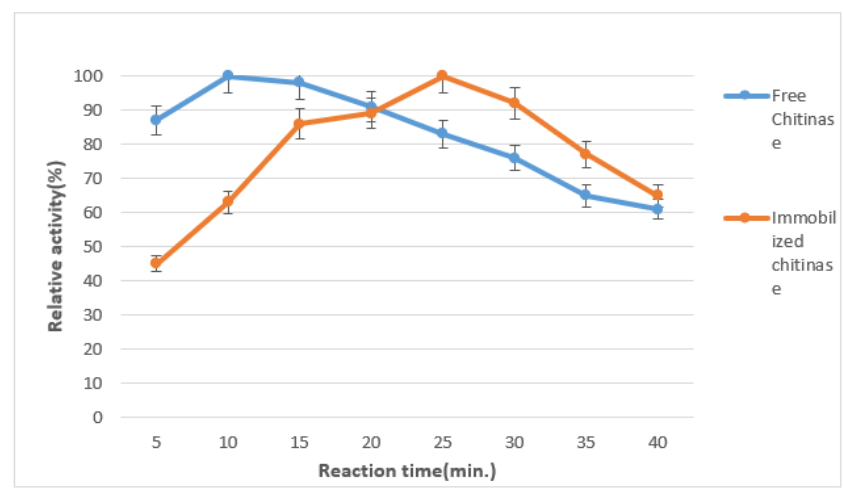

Fig 2. Effect of reaction time on free and immobilised chitinase

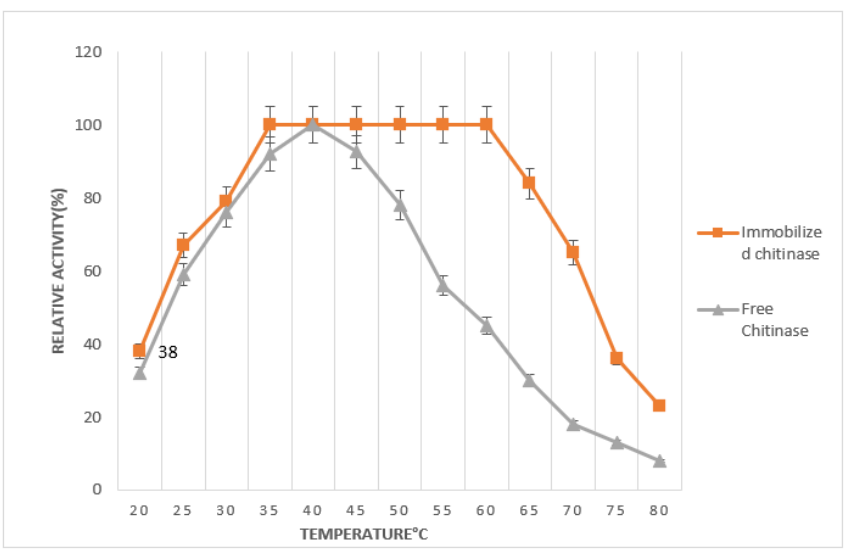

Fig 3. Effect of temperature on free and immobilised chitinase

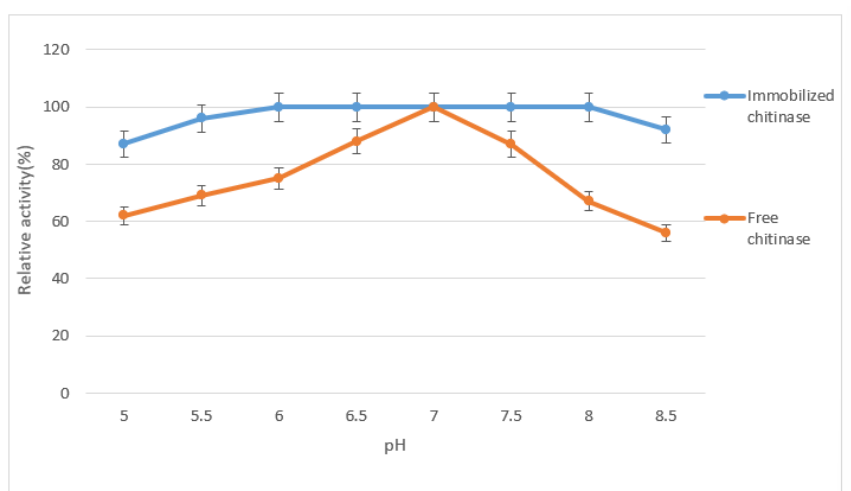

Fig 4. Effectof $\mathrm{pH}$ on free and immobilised chitinase 
by the enzyme losing its flexibility for substrate binding, resistance to substrate diffusion, or a barrier in the active region. This drop in Vmax could be due to the enzymes' interaction with the functional groups on the bead surface limiting the accessibility of chitin molecules to the active site.

The thermo stability of the enzyme is essential to fulfil industrial criteria; therefore, the thermal stability of chitinase after entrapment was investigated by placing the immobilised chitinase at $40^{\circ} \mathrm{C}, 50^{\circ} \mathrm{C}$, and $60^{\circ} \mathrm{C}$ for 2.0 . In comparison to free chitinase, the stability of chitinase following immobilisation was improved. Free chitinase lost more than 45 percent of its activity at temperatures above $60^{\circ} \mathrm{C}$, whereas immobilised chitinase retained 90 percent of its activity at $60^{\circ} \mathrm{C}$ even after 2.0 hours (Fig. 6). Thermal stability experiments revealed that Penicillium chrysogenum immobilised chitinase maintained full activity for 120 minutes at $(50 \text { and } 55)^{\circ} \mathrm{C} .{ }^{(10)}$.

One of the most important objectives of immobilization was the stability of the enzyme. The residual activity of immobilised chitinase was determined in 5-day intervals up to 20 days. It was observed that the chitinase entrapped in alginate spheres retained $92 \%$ activity at room temperature after 20 days.

Reusability of the biocatalyst is a very important factor from an economic perspective. Immobilised beads were washed after every cycle with buffer and used again for the next reaction after 16 cycles. The study revealed that the immobilised enzyme has great potential to retain its $80 \%$ activity even after 16 cycles. The immobilised chitinase of Penicillium chrysogenum could retain most of its activity after three cycles ${ }^{(10)}$.

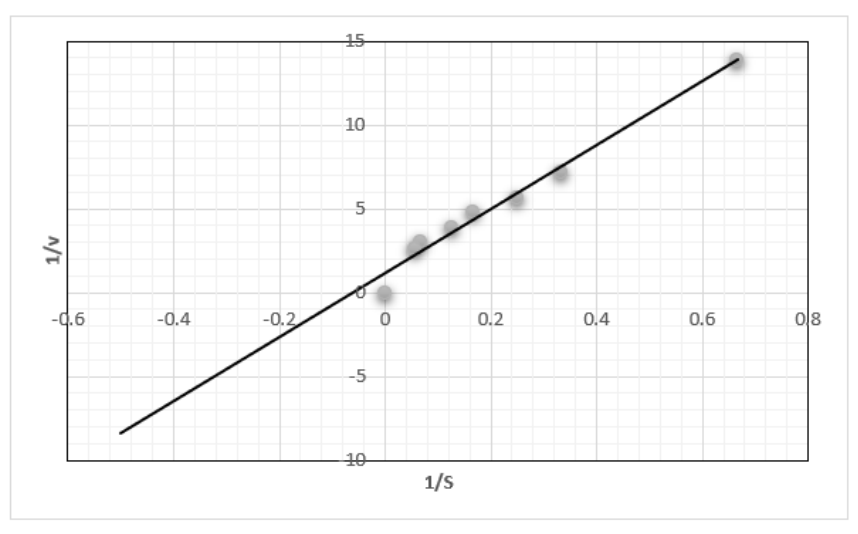

Fig 5. LB plot of imobilized chitinase

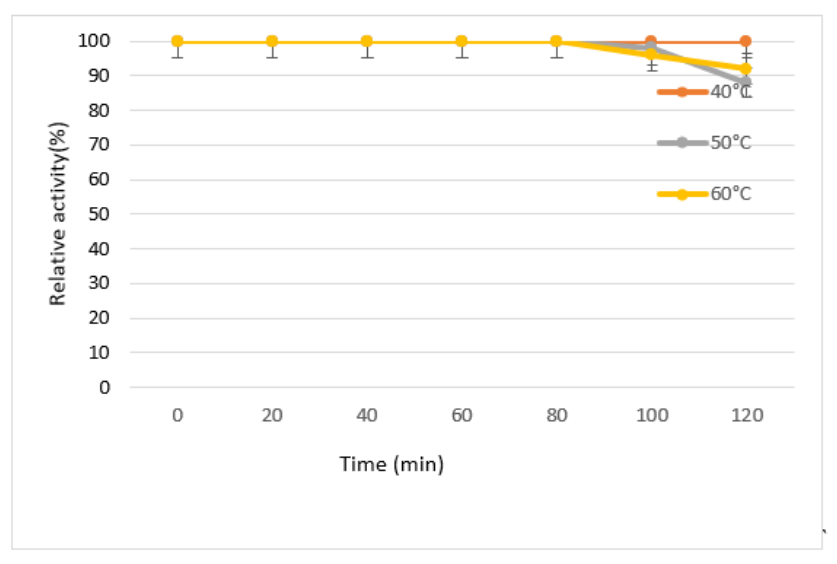

Fig 6. Thermal stability of immobilised K. gibsonii Mb126 chitinase

The results of the study on the impact of various chemicals are presented in Table 2. The influence of different chemicals on immobilised chitinase activity was examined. It was observed that tween 20 and triton x100 slightly had an excitatory effect on immobilised chitinase activity. However, tween 80, EDTA, and SDS exhibited inhibitory action on immobilised chitinase. $\beta$ mercapto ethanol and dithiothreitol did not affect enzyme activity. 
Table 2. Effectof different chemicals on immobilised chitinase activity

\begin{tabular}{llllll}
\hline \multirow{2}{*}{ Chemicals } & \multicolumn{5}{c}{ Relative enzyme activity $(\%)^{*}$ at different concentrations } \\
\cline { 2 - 6 } & $2 \mathrm{mM}$ & $4 \mathrm{mM}$ & $6 \mathrm{mM}$ & $8 \mathrm{mM}$ & $10 \mathrm{mM}$ \\
\hline Triton X-100 & $106 \pm 1.3$ & $128 \pm 0.76$ & $111 \pm 3.5$ & $45 \pm 2.9$ & $19 \pm 2.5$ \\
Tween- 20 & $121 \pm 1.2$ & $128 \pm 1.65$ & $106 \pm 1.3$ & $100 \pm 1.7$ & $100 \pm 1.64$ \\
Tween- 80 & $46 \pm 2.3$ & $48 \pm 2.6$ & $33 \pm 2.43$ & $31 \pm 1.2$ & $25 \pm 1.87$ \\
SDS & $32 \pm 2.4$ & $29 \pm 1.9$ & $25 \pm 1$ & $18 \pm 1.62$ & $9 \pm 1.34$ \\
EDTA & $64 \pm 0.98$ & $61 \pm 2.3$ & $15 \pm 2.6$ & $13 \pm 2.2$ & $15 \pm 1.3$ \\
$\beta$ - mercaptoethanol & $100 \pm 1.56$ & $100 \pm 3.4$ & $100 \pm 1.53$ & $100 \pm 1.6$ & $100 \pm 1.87$ \\
Dithiothreitol & $100 \pm 2.32$ & $98 \pm 2.32$ & $99 \pm 1.8$ & $100 \pm 2.78$ & $100 \pm 1.34$ \\
\hline
\end{tabular}

${ }^{*}$ Activity of the control was taken as $100 \%$

\subsection{In vitro antifungal assay}

Using the agar-disk diffusion method, free chitinase and immobilised chitinase were evaluated against $A$. flavus, which was isolated from rotten lemon fruit. Mycelium growth inhibition was observed at $27^{\circ} \mathrm{C}$ for 8 days after inoculation, demonstrating that both free and immobilised chitinase administration can inhibit A. flavus fungal mycelium extension (Table 3 ). Free chitinase inhibited mycelial growth $56 \pm 2.45 \%$. Immobilised chitinase, on the other hand, entirely stopped fungal growth. Up to $0.06 \mathrm{~g}$ of bead, the rate of growth reduction by immobilised chitinase was directly proportionate; after that, it remained $100 \%$. The greater effectiveness of immobilised chitinase may be due to the conserved, controlled and consistent release of chitinase, resulting in a stronger inhibitory effect. On the basis of the findings of the in vitro inhibition of mycelial growth assay, immobilised chitinase $(0.06 \mathrm{~g})$ was subjected to in vivo experimental analysis in A. flavus-infected lemon fruits. Figure 7 presents the observations from the in vivo study of the immobilised chitinase using lemon fruit infected by A. flavus. The statistical analysis proved that the lowest percentage of decayed lemons was recorded for immobilised chitinase $(5+2.34 \%)$, followed by free chitinase $(34 \%)$ on day 9. All positive control lemon fruits (infested by A. flavus only) were under decay and spoilage after 7 days.

A. flavus is an important postharvest pathogen. It can cause spoilage in different kinds of food and can be controlled by suitable chemical fungicides. However, due to the negative effects of these fungicides on our environment, non-target health hazards on animals and plants, and the development of fungicide resistance in microorganisms, alternative control methods are desperately needed. A minimal number of studies have been focused on the efficient utilisation of green preservatives against fungal infestation and mycotoxin contamination of fruits. To reduce post-harvest decay on lemons, Sebahat and Funda (2021) used pectinase-negative Metschnikowia sp. with chitinase activity as biocontrol agents against green and blue Penicillium ${ }^{(11)}$. Nanoemulsion-based essential oils on the surface of fruits can prevent fungi ${ }^{(12)}$. Chitinase enzymes can also be utilised as a green alternative to antifungal chemical disinfectants because they can hydrolyse chitin present in the fungal cell wall ${ }^{(13)}$. Large scale applications of free chitinase to control postharvest decay by fungi are restricted due to the operational instability and thermal denaturation of the soluble form of the enzyme. This study clearly demonstrated that immobilised chitinase has higher thermostability, operational stability, reusability, and higher antifungal properties compared to its free counterpart. Therefore, the most effective treatments to control the postharvest decay were those based on K. gibsonii Mb126 immobilised chitinase. To the best of our knowledge, it was the first report on the investigation of the antifungal activity of immobilised chitinase for controlling postharvest decay of lemon fruits.

Table 3. Antifungal activity of free and immobilised chitinase

\begin{tabular}{llll}
\hline Free Chitinase (U/mL) & Mycelial Inhibition (\%) & Immobilised chitinase (amount of bead 'g') & Mycelial inhibition (\%) \\
\hline 0.1 & $36 \pm 1.3$ & 0.02 & $65 \pm 1.3$ \\
0.2 & $42 \pm 2.54$ & 0.04 & $86 \pm 1.35$ \\
0.3 & $48 \pm 2.67$ & 0.06 & $100 \pm 1.56$ \\
0.4 & $51 \pm 1.65$ & 0.08 & $100 \pm 1.51$ \\
0.5 & $56 \pm 1.09$ & 0.1 & $100 \pm 1.25$ \\
0.6 & $57 \pm 1.56$ & 0.12 & $100 \pm 1.16$ \\
0.7 & $56 \pm 1.34$ & 0.14 & $100 \pm 1.28$ \\
0.8 & $56 \pm 1.25$ & 0.16 & $100 \pm 1.17$ \\
\hline
\end{tabular}




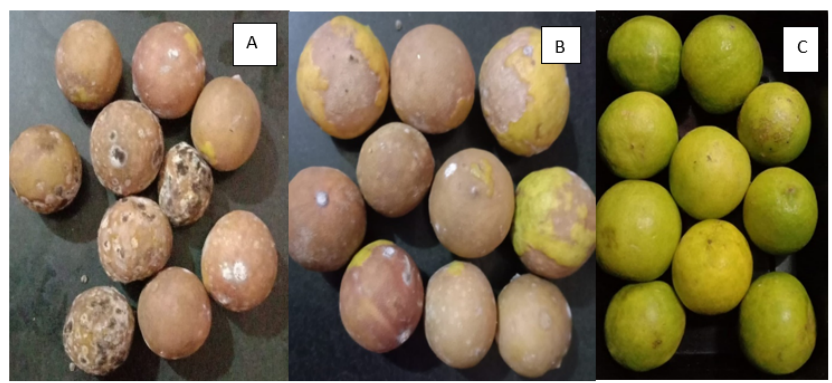

Fig 7. a, b, c. In vivo analysis of antifungal activity immobilised chitinase in lemons infected by Aspergillus flavus after 9 days. A) Lemons infected by Aspergillus flavus alone B) Lemons infected by Aspergillus flavus and treated with Kurthia gibsonii Mb126 free chitinase C) Lemons infected by Aspergillus flavus and treated with immobilised Kurthia gibsonii Mb126 chitinase

\section{Conclusion}

Chitinase isolated from K. gibsonii Mb126 was immobilised with an 83.3\% immobilisation yield. Surface characterization of alginate hydrogel spheres was done by scanning electron microscopy. The factors determining the efficiency of the immobilisation process were optimised. $3 \%$ of sodium alginate and $0.2 \mathrm{M}$ calcium chloride were suitable with 120 minutes of curing time. The immobilised chitinase exhibited enhanced functionality, and it exhibited $\mathrm{pH}$ tolerance and thermal stability. The kinetic parameters were analysed. The immobilised chitinase of $K$. gibsonii Mb126 can be reused many times, and it shows good storage stability. Agar-disk diffusion experiments proved that the immobilised chitinase of $K$. gibsonii Mb126 had a strong fungicidal effect against $A$. flavus. Experimental in vivo analysis conducted on lemons revealed the efficiency of immobilised chitinase to inhibit postharvest decay after infection with A. flavus. Post-harvest decay on lemon fruits was more successfully managed by immobilised chitinase of K. gibsonii Mb126, and this could be utilised as a sustainable, eco-friendly fungicide. To the best of our knowledge, this is the one and only study report about the antifungal nature of chitinase against a fungus that causes post-harvest decay in lemon fruits.

\section{References}

1) Makavana JM, Makwana PJ, Kukadiya VD, Joshi AM. Post-Harvest Losses of Lemon Fruits: An Assessment of Microbial Floral Strength during PostHarvest Handling. International Journal of Current Microbiology and Applied Sciences. 2018;7(05):1184-1188. Available from: https://dx.doi.org/10.20546/ ijcmas.2018.705.144.

2) Omotayo OP, Omotayo AO, Mwanza M, Babalola OO. Prevalence of Mycotoxins and Their Consequences on Human Health. Toxicological Research. 2019;35(1):1-7. Available from: https://dx.doi.org/10.5487/tr.2019.35.1.001.

3) Dukare A, Paul S, Arambam A. Isolation and efficacy of native chitinolytic rhizobacteria for biocontrol activities against Fusarium wilt and plant growth promotion in pigeon pea (Cajanus cajan L.). Egyptian Journal of Biological Pest Control. 2020;30(1):56-56. Available from: https://dx.doi.org/10.1186/ s41938-020-00256-7.

4) Cavalcante FTT, Cavalcante ALG, de Sousa IG, Neto FS, dos Santos JCS. Current Status and Future Perspectives of Supports and Protocols for Enzyme Immobilization. Catalysts. 2021;11(10):1222-1222. Available from: https://dx.doi.org/10.3390/catal11101222.

5) Khan MR. Immobilized enzymes: a comprehensive review. Bulletin of the National Research Centre. 2021;45(1):207-207. Available from: https: //doi.org/10.1186/s42269-021-00649-0.

6) Mohammadi M, Heshmati MK, Sarabandi K, Fathi M, Lim LT, Hamishehkar H. Activated alginate-montmorillonite beads as an efficient carrier for pectinase immobilization. International Journal of Biological Macromolecules. 2019;137:253-260. Available from: https://dx.doi.org/10.1016/j.ijbiomac. 2019.06.236.

7) Malhotra I, Basir SF. Immobilization of invertase in calcium alginate and calcium alginate-kappa-carrageenan beads and its application in bioethanol production. Preparative Biochemistry \& Biotechnology. 2020;50(5):494-503. Available from: https://dx.doi.org/10.1080/10826068.2019.1709979.

8) Zhang H, Cheng J, Ao Q. Preparation of Alginate-Based Biomaterials and Their Applications in Biomedicine. Marine Drugs. 2021;19(5):264-264. Available from: https://dx.doi.org/10.3390/md19050264.

9) Kidibule PE, Costa J, Atrei A, Plou FJ, Fernandez-Lobato M, Pogni R. Production and characterization of chitooligosaccharides by the fungal chitinase Chit42 immobilized on magnetic nanoparticles and chitosan beads: selectivity, specificity and improved operational utility. RSC Advances. 2021;11(10):5529-5536. Available from: https://dx.doi.org/10.1039/d0ra10409d.

10) Mansour SH, Abdel-Fattah AM, Esawy MA, Ahmed EF, Haroun AA, Hussein MA, et al. Immobilization, Thermodynamic studies and Application of Chitinase enzyme from Penicillium chrysogenum. Egyptian Journal of Aquatic Biology and Fisheries. 2019;23(3):527-544. Available from: https: //dx.doi.org/10.21608/ejabf.2019.48698.

11) Oztekin S, Karbancioglu-Guler F. Bioprospection of Metschnikowia sp. isolates as biocontrol agents against postharvest fungal decays on lemons with their potential modes of action. Postharvest Biology and Technology. 2021;181:111634-111634. Available from: https://dx.doi.org/10.1016/j.postharvbio. 2021.111634. 
12) Das S, Ghosh A, Mukherjee A. Nanoencapsulation-Based Edible Coating of Essential Oils as a Novel Green Strategy Against Fungal Spoilage, Mycotoxin Contamination, and Quality Deterioration of Stored Fruits: An Overview. Frontiers in Microbiology. 2021;12:768414-768414. Available from: https: //dx.doi.org/10.3389/fmicb.2021.768414.

13) Poria V, Rana A, Kumari A, Grewal J, Pranaw K, Singh S. Current Perspectives on Chitinolytic Enzymes and Their Agro-Industrial Applications. Biology. 2021;10(12):1319-1319. Available from: https://dx.doi.org/10.3390/biology10121319. 